\title{
PENGARUH POTONGAN HARGA DAN PENATAAN PRODUK TERHADAP KEPUTUSAN PEMBELIAN KONSUMEN DI MATAHARI DEPARTEMEN STORE PEKALONGAN (Studi Kasus Produk Cardinal Shoes Ladies)
}

\author{
Rizka Ariyanti ${ }^{1)}$, M. Iqbal Notoatmojo ${ }^{2)}$, Aria Mulyapradana, ${ }^{3)}$ Putri S. ${ }^{4)}$ \\ $1,2,3$ Politeknik Pusmanu Pekalongan \\ Email : ${ }^{1}$ rizkaariyanti81@gmail.com, ${ }^{2}$ iqbalbwox@gmail.com, ${ }^{3}$ ariamulyapradana@gmail.com \\ ${ }^{4}$ putriseptyoningrum@gmail.com
}

\begin{abstract}
This study aims to examine and analyse the effect of price cuts, product arrangement on purchasing decisions on consumer purchasing decisions at Matahari Department Store Pekalongan, especially Cardinal Shoes Ladies.To test these variables, the researcher used 100 consumer respondents in the Matahari Department Store Pekalongan. The type of research used is explanatory research. Data collection techniques using interview techniques and questionnaires. The type of data used in this study is primary data. Furthermore, the data that has been collected is analysed quantitatively using multiple regression using the SPSS program. The results of the research simultaneously show that the variable price discount has an effect on purchasing decisions, the variable of product arrangement has an effect on purchasing decisions, while for the partial research results, the variables of Price Discounts and Product Charges affect purchasing decisions.
\end{abstract}

Keynote: Price discount, product arrangement, purchasing decisions

\section{PENDAHULUAN}

Kompetisi usaha yang ketat di antara perusahaan mengakibatkan banyak di antaranya tidak mampu bersaing dan bertahan dalam usahanya (Philip Kotler, 1990:85). Hal ini terlihat dari menurunnya daya minat membeli masyarakat terhadap suatu barang maupun jasa yang salah satunya disebabkan oleh kondisi perekonomian yang kurang membaik. Menurunnya daya beli konsumen berdampak pada tingkat penjualan. Konsumen akan melakukan seleksi yang ketat dan kritis dalam melakukan transaksi pembelian suatu produk yang berdampak pula dalam menentukan pilihannya.

Perekonomian di masa pandemi menyebabkan daya beli masyarakat semakin menurun dan berpengaruh pula terhadap tingkat penjualan. Apabila konsumen akan melakukan transaksi pembelian sebuah produk, konsumen akan lebih kritis dan selektif dalam menentukan pilihan.
Untuk memenangkan persaingan dan menarik minat pembeli dalam membeli produknya maka banyak perusahaan melakukan berbagai cara atau strategi dalam bisnisnya, hal yang sering dilakukan oleh hampir semua perusahaan retail yakni melakukan kegiatan promosi.

Strategi pemasaran yang dibuat oleh perusahaan memiliki tujuan agar perusahaanya mampu berkompetisi dengan perusahaan lain agar dapat memenangkan kompetisi tersebut. Strategi yang digunakan guna memenangkan kompetisi tersebut yakni dengan menerapkan marketing mix. Adapun unsur-unsur yang terdapat di marketing mix seperti harga produk, saluran produk, penyaluran dan promosi. Unsur-unsur tersebut menjadi acuan oleh perusahaan dalam melakukan strategi pemasaran. Unsur promosi di marketing mix menjadi salah satu unsur yang digunakan hampir sebagian besar di semua perusahaan.

Promosi sebagai media penyampaian komunikasi kepada konsumen, guna 
tersampaikan secara efektif dan efisien maka perusahaan dalam melakukan kegiatan promosi harus dilakukan strategi yang tepat agar tepat sasaran dan tercapainya tujuan yang telah ditetapkan. Pemberian potongan harga menjadi salah satu alternatif yang bisa dinilai efektif dan efisien guna dapat dengan cepat dalam menarik konsumen.

Di samping pemberian potongan harga, display atau penataan produk juga dapat mempengaruhi keputusan pembelian konsumen. Penataan produk memiliki maksud yakni guna memikat dan mengumpulkan pembeli agar terpesona dan menentukan pilihannya untuk produk tersebut.

Selain itu pula, display atau penata produk berguna untuk mengikat pembeli dan membentuk rasa nyaman dalam membeli produk yang dipilihnya sehingga pembeli timbul rasa puas dan loyalitas tetap terjaga.

Hal ini sejalan dengan beberapa riset yang dilakukan oleh peneliti sebelumnya di antaranya adalah riset yang dilakukan oleh Sugeng Setyo Nuroho (2017) menyatakan bahwa keputusan pembelian dipengaruhi oleh potongan harga, penataan produk dan lokasi. Hal senada yang diungkapkan oleh Josep Tolisindo (2017) di penelitiannya bahwa keputusan pembelian dipengaruhi oleh potongan harga. Dan riset yang dilakukan oleh Vicky mengatakan bahwa impulse buying dipengaruhi oleh price discount dan bonus pack.

Hal ini berbeda dengan yang diungkapkan oleh Anggun Prabarini ( 2018), di mana peneliti mengatakan bahwa tidak terdapat pengaruh signifikan antara promosi terhadap keputusan pembelian, akan tetapi potongan harga terhadap pembelian konsumen memiliki signifikan serta untuk promosi penjualan dan potongan harga terhadap keputusan pembelian memiliki pengaruh yang signifikan.

Bersumber pada hasil riset terdahulu maka peneliti tertarik untuk mengkaji kembali lebih lanjut untuk meneliti pengaruh potongan harga dan penataan produk terhadap keputusan pembelian konsumen di Matahari Departemen Store Pekalongan khususnya Cardinal Shoes Ladies.
Adapun rumusan masalah di riset ini yakni bagaimana pengaruh potongan harga, penataan produk terhadap keputusan pembelian konsumen pada produk Cardinal Soes Laedies di Matahari Departemen Store Pekalongan. Sedangkan tujuan dari riset ini yakni untuk menguji dan menganalisis pengaruh potongan harga dan penataan produk terhadap keputusan pembelian konsumen di Matahari Department Store Pekalongan.

\section{LANDASAN TEORI DAN PENGEM- BANGAN HIPOTESIS}

\subsection{Potongan Harga (Diskon)}

Soemarso mengatakan bahwa price discount atau potongan harga penjualan merupakan pemberian potongan harga dilakukan jika pembayaran yang dilakukan lebih cepat dari batas waktu kredit yang telah ditentukan. Sejalan yang diutarakan oleh Ismaya di mana adanya kesepakatan potongan terhadap harga jual apabila pembayaran dapat diselesaikan dalam tempo yang cepat dari batas yang telah ditetapkan. Sedangkan Simamora mengatakan bahwa discount atau potongan harga merupakan penawaran potongan tunai kepada konsumen dalam pembelian barangbarang secara angsuran (Kasimin, et all, 2014).

Ben Lowe mengutarakan bahwa potongan harga adalah alternatif dari beberapa cara dalam promosi penjualan yang diterapkan di perusahaan yang ditujukan pada konsumennya. Potongan harga menjadi hal yang disukai oleh konsumen dikarenakan konsumen langsung mendapatkan pengurangan harga dari produk yang dipilihnya.

Potongan harga menjadi alternatif dalam strategi bisnis yang diterapkan di perusahaan dikarenakan efektivitasnya guna memikat minat membeli dari konsumen. Adapun maksud dari dibuatnya program potongan harga yakni menjaga kestabilan dalam perputaran uang, hal ini berguna untuk mendanai kegiatan operasional, tenaga kerja dan biaya lainnya yang berhubungan dengan siklus hidup perusahaan.

Terdapat dua orang atau lebih yang terlibat dalam kegiatan bisnis perdagangan yakni sebagai pedagang dan konsumen. Kesepakatan tentang barang, harga atau potongan harga 
dilakukan sebelum terjadinya kegiatan transaksi antara pedagang dengan konsumen. Di samping itu pula pemberian potongan kepada konsumen diharapkan dapat mempengaruhi keputusan pembelian suatu produk yang ditawarkan.

$\mathrm{H}_{1}$ : Terdapat pengaruh positif antara potongan harga dengan keputusan pembelian.

\subsection{Penataan Produk}

Penataan produk merupakan salah satu cara untuk menata atau mendisain produk ke dalam layout suatu toko seperti cara meletakkan produk beserta perangkat lainnya, teknik penataan barang dagangan (merchandise) sehingga akan menghasilkan layout yang bagus.

Penataan produk merupakan salah satu cara yang digunakan dalam penyusunan barang dagangan di toko serta memperhatikan beberapa unsur di antaranya mengelompokkan jenis dan manfaat dari produk, keapikan produk dan keindahan, hal tersebut bertujuan untuk memikat dan menghimpun konsumen guna berminat untuk menengok dan mengambil serta membeli produk yang diinginkan.

Maksud dari penataan produk yakni terciptanya citra niaga (store image), mempermudah konsumen dalam pencarian produk yang diinginkan, mengedepankan model dan merek dari produk yang dijual, dapat menaikkan penjualan produk, dan menginformasikan pada konsumen mengenai produk baru. Adapun syarat-syarat yang perlu diperhatikan di penataan produk di antaranya teratur dan resik, tidak sukar dalam pencarian, gampang terlihat, terjangkau dan terjaga. Di samping itu pula, ada empat elemen utama yang perlu diperhatikan dalam store atmosphere yakni bagian luar dari toko, interior umum, tata letak toko dan interior dari display (Adyarinanda \& Yuliati, 2017).

Penataan produk menjadi fokus utama yang perlu menjadi perhatian dari perusahaan dikarenakan penataan produk yang baik dan tepat memiliki dampak yang positif seperti minat dan keinginan membeli produk yang ditawarkan.

Hal tersebut diperkuat oleh riset yang dilakukan oleh Adyarinanda dan Yuliati di mana store atmosphere berpengaruh signifikan terhadap keputusan pembelian konsumen sebesar 65,1\% (Adyarinanda \& Yuliati, 2017).
Hasil riset yang dilakukan oleh Katarika dan Syahputra dapat memperkuat riset ini karena dari hasil riset tersebut menghasilkan bahwa store atmosphere berpengaruh positif dan signifikan terhadap pembelian pada Kopi Ireng dan Kopi Selasar Sunaryo (Kartika \& Syahputra, 2017).

Dari beberapa riset terdahulu maka di riset ini peneliti melakukan hipotesa sebagai berikut;

$\mathrm{H}_{2}$ : Terdapat pengaruh positif antara penataan produk dengan keputusan pembelian.

\subsection{Keputusan Pembelian}

Keputusan merupakan aktivitas yang dilakukan untuk memilah dua atau beberapa alternatif, adapun analisis ketika pengambilan keputusan melingkupi penentuan dalam memilih dua atau beberapa alternatif serta mempertimbangkan proses yang terjadi sebelum dan sesudah diambilnya pilihan (Mulyapradana \& Anjarini, 2020:168). Hal senada yang diungkapkan oleh Syafaruddin dan Anzizah (Tukino, 2014) dikemukankan bahwa pengambilan keputusan merupakan tindakan yang dilakukan dalam memilih di antara dua pilihan agar dapat terselesaikannya problem yang dihadapinya.

Kotler (2012:204) mengatakan bahwa ada lima tahapan yang harus dilalui oleh konsumen dalam melakukan proses keputusan pembelian di antaranya yakni mengenali kebutuhannya, mencari informasi, melakukan alternatf pertimbangan, keputusan pembelian dan perilaku setelah pembelian. Seperti halnya yang diungkapkan oleh Ivancevich (Mulyapradana, Hakim, Anjarini, et al., 2021) di mana dalam pengambilan keputusan ada sembilan tahapan yang perlu diperhatikan diantaranya adalah (1) tetapkan target, tujuan yang jelas dan pengukuran hasil; (2) identifikasi masalah; (3) adanya prioritas; (4) memperhitungkan pemicu dari problem; (5) pengembangan solusi; (6) mempertimbangkan alternatif solusi; (7) pemilihan solusi, (8) penerapan; dan (9) tindak lanjut. Ada lima unsur yang diungkapkan oleh Terry (Lipursari, 2013) (Mulyapradana, Hakim, Jamaludin Kharis, et al., 2021) terkait dengan pengambilan keputusan yakni perasaan, pengalaman, fakta, wewenang dan rasional.

Hal ini diperkuat dengan riset yang dilakukan oleh Widodo di mana riset tersebut 
menyatakan bahwa diskon, display produk dan lokasi secara bersamaan memiliki pengaruh yang signifikan terhadap keputusan pembelian di Toko D'Sport Kediri (Widodo, 2017). Senada yang diungkapkan oleh Meidasari dan Khoirina di risetnya mengatakan bahwa potongan harga pada display toko memiliki pengaruh terhadap keputusan pembelian impulsive (Meidasari M \& Khoirina, 2021)(Meidasari M \& Khoirina, 2021).

Bersumber dari latar belakang tersebut berikut ini adalah kerangka pemikiran di riset ini:

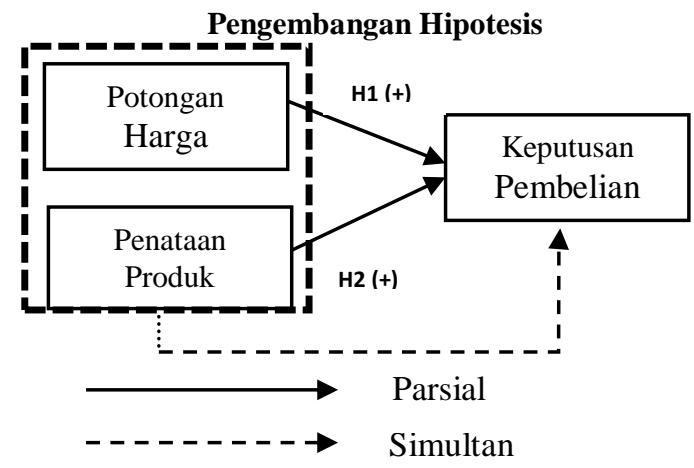

Gambar 1. Kerangka Berfikir

\section{METODE PENELITIAN}

Riset ini memakai bentuk explanatory, bertujuan guna menganalisa relasi antar variabel di dalam riset tersebut (Ary Dwi, 2017:32).

Variabel penelitian merupakan segala sesuatu yang ditetapkan oleh peneliti guna dipelajari sehingga memperoleh informasi terkait penelitian serta dapat ditarik kesimpulannya (Sugiyono, 2013:38). Di riset ini terdapat variabel bebas (independent) yang merupakan variabel mempengaruhi variabel lainnya dan variabel terikat (dependent) merupakan variabel yang dipengaruhi.

Populasi dan sampel ialah objek atau subjek dari riset yang diteliti yang memiliki kriteria yang telah ditentukan oleh peneliti agar dapat ditarik kesimpulannya. Di riset ini populasinya yakni konsumen produk merek Cardinal Shoes Ladies di Matahari Departement Store Pekalongan yang tidak diketahui jumlah pastinya merupakan populasi dari penelitian ini.
Kemudian untuk sampel pada riset yakni sebanyak 100 responden di mana hasil ini diketahui dari jumlah hasil penyebaran kuesioner yang berada di Matahari Departement Store Pekalongan.

Adapun metode yang digunakan untuk mendapatkan data riset yaitu dengan teknik wawancara, pemberian kuesioner dan studi pustaka.

a. Metode wawancara, yaitu metode mengumpulkan data melalui tanya jawab secara langsung kepada pengelola Matahari Departemen Store Pekalongan terkait konsumen yang berada di Matahari Departement Store Pekalongan.

b. Metode kuesioner, yaitu teknik pengumpulan data dilakukan dengan cara memberi seperangkat pertanyaan atau pernyataan tertulis kepada responden untuk dijawab oleh responden. Dalam hal ini yang dimaksud adalah responden yang menggunakan produk merek Cardinal Shoes Ladies. Berikut adalah indikator dan pemberian skor atau bobot pada setiap pertanyaan kuesioner.

Tabel 1 Indikator dan Bobot Kuesioner

\begin{tabular}{lll}
\hline \multicolumn{1}{c}{ Variabel } & Konsep Variabel & \multicolumn{1}{c}{ Indikator } \\
\hline Potongan & Potongan harga & 1. Diskon musiman \\
harga (X1) & yaitu pengurangan & 2. Frekuensi \\
& $\begin{array}{l}\text { harga produk dari } \\
\text { harga normal da- }\end{array}$ & 3. Jenis produk yang \\
& lam periode & didiskon \\
& tertentu. & Kesesuaian tingkat \\
& Penataan produk & 1.Kerapihan \\
Penataan & yaitu perapihan & penyusunan. \\
produk & suatu produk dalam & 2.Ketertarikan \\
(X2) & suatu toko. & pemajangan. \\
& & 3.Keanekaragaman jenis. \\
& & 4.Penambahan hiasan. \\
& Serangkaian proses & 1.Pengenalan kebutuhan. \\
Keputusan & yang dilalui oleh & 2.Pencarian informasi \\
pembelian & calon konsumen & 3.Pemilihan alternative \\
(Y) & dalam memutuskan & 4.Keputusan pembelian \\
& tindakan & \\
& pembelian. & \\
\hline Sumber &
\end{tabular}

Sumber : Data primer diolah

Skor atau bobot pada setiap pertanyaan kuesioner :

1. Sangat setuju, diberi skor 5

2. Setuju, diberi skor 4

3. Netral, diberi skor 3

4. Tidak setuju, diberi skor 2

5. Sangat tidak setuju, diberi skor 1 


\subsection{Variabel Independent}

Variabel independent adalah variabel yang dikenal selaku variabel stimulus, prediktor, dan antesenden. Variabel independent atau variabel bebas merupakan mempengaruhi variabel dependent (Sugiyono, 2013:39). Untuk riset yang dilakukan oleh peneliti terdapat dua variabel independent yakni potongan harga sebagi X1 dan penataan produk sebagai X2 .

\subsection{Variabel Dependent}

Variabel dependent atau variabel output, kriteria, dan konsekuen. Variabel dependent atau variabel terikat adalah variabel yang dipengaruhi atau yang menjadi akibat, karena adanya variabel bebas (Sugiyono, 2013:39). Untuk riset yang dilakukan oleh peneliti yakni keputusan pembeli sebagai Y.

\subsection{Analisis Regresi Linear Berganda}

Analisis regresi linear berganda berguna untuk memperkirakan pengaruh dua variabel variabel bebas atau lebih terhadap satu variabel terikat. Regresi linear berganda digunakan untuk menguji pengaruh antara variabel independent (diferensiasi produk) dengan variabel dependent (kepuasan konsumen). Analisis yang digunakan untuk mengetahui arah hubungan antara variabel memiliki hubungan positif atau negatif. Serta digunakan untuk memprediksi nilai dari variabel dependent apabila nilai variabel independent mengalami kenaikan atau penurunan. Serta dianalisis dengan uji validitas, uji reliabilitas, uji multikolinearitas, uji heteroskedasitas, uji analisis regresi linear berganda, uji t dan uji koefisian determinasi. Perhitungan akan dilakukan dengan bantuan program SPSS versi 22. Persamaan regresi ganda dirumuskan sebagai berikut :

\section{$Y=a+b 1 X 1+b 2 X 2+e$}

\section{HASIL ANALISIS DAN PEMBA-HASAN}

\subsection{Uji Reliabilitas}

Pada tabel 2 yakni uji reliabilitas menghasilkan nilai Cronbach's Alpha yakni 0.568 dari 12 butir pernyataan. Nilai tersebut menunjukan bahwa kuesioner yang dibuat oleh peneliti di riset ini dikategorikan konsisten (reliable).
Tabel 2 Uji Reliabitas

\begin{tabular}{|c|c|}
\hline \multicolumn{2}{|c|}{ Reliability Statistics } \\
\hline Cronbach's Alpha & N of Items \\
\hline .568 & 12 \\
\hline
\end{tabular}

\subsection{Uji Multikolinearitas}

Riset ini menggunakan uji multikolinearitas gunanya untuk menguji model regresi yang mana untuk mengetahui atau ditemukannya hubungan yang kuat di antara variabel independent. Untuk mengetahui multikolinearitas ada atau tidaknya di riset ini dengan cara melihat besarnya nilai toleransi value atau variance inflation factor (VIF). Apabila nilai VIF < 0,10 atau VIF $>10$ maka terjadi multikolinearitas. Bersumber pada tabel 3 yakni uji multikolinearitas menunjukkan bahwa nilai VIF lebih besar dari 0,10 dan lebih kecil dari 10 berarti tidak terjadi adanya penyimpangan asumsi klasik multikolinearitas.

\section{Tabel 3 Uji Multikolinearitas}

\begin{tabular}{|c|c|c|c|c|c|c|}
\hline & \multirow{2}{*}{ Model } & \multicolumn{2}{|c|}{$\begin{array}{l}\text { Unstandardize } \\
\text { d Coefficients }\end{array}$} & \multirow{2}{*}{$\begin{array}{c}\text { Standardized } \\
\text { Coefficients } \\
\text { Beta }\end{array}$} & \multirow{2}{*}{$\mathrm{T}$} & \multirow{2}{*}{ Sig. } \\
\hline & & B & $\begin{array}{l}\text { Std. } \\
\text { Error }\end{array}$ & & & \\
\hline \multirow[t]{3}{*}{1} & (Constant) & 5.896 & 1.153 & & 5.113 & .000 \\
\hline & $\begin{array}{l}\text { POTONGA } \\
\text { N HARGA } \\
(\mathrm{X} 1)\end{array}$ & .644 & .071 & .677 & 9.071 & .000 \\
\hline & $\begin{array}{l}\text { PENATAAN } \\
\text { BARANG } \\
(\mathrm{X} 2)\end{array}$ & -.150 & .059 & -.189 & -2.535 & .013 \\
\hline
\end{tabular}

\subsection{Uji Heteroskedasitas}

Nilai signifikansi yang kurang dari 0,05 berarti model regresi terjadi masalah heteroskedasitas. Bersumber pada tabel 4 yakni uji heteroskedasitas diperoleh hasil sebagai berikut bahwa korelasi antara potongan harga dengan Unstandardized Residual menghasilkan nilai signifikansi 0,775 dan korelasi antara penataan produk dengan Unstandardized residual menghasilkan nilai signifikansi 0.825 . Karena nilai signifikansi korelasi lebih besar dari 0,05, maka dapat disimpulkan bahwa pada model regresi tidak ditemukan adanya masalah heteroskedastisitas. 
Tabel 4 Uji Heteroskedastisitas

\begin{tabular}{|c|c|c|c|c|c|}
\hline \multicolumn{6}{|c|}{ Correlations } \\
\hline & & & $\begin{array}{c}\text { POTON } \\
\text { GAN } \\
\text { HARGA } \\
\text { X1 }\end{array}$ & $\begin{array}{l}\text { PENAT } \\
\text { AAN } \\
\text { PRODU } \\
\text { K X2 }\end{array}$ & $\begin{array}{l}\text { Unstandar } \\
\text { dized } \\
\text { Residual }\end{array}$ \\
\hline \multirow[t]{9}{*}{$\begin{array}{l}\text { Spear } \\
\text { man's } \\
\text { rho }\end{array}$} & \multirow[t]{3}{*}{$\begin{array}{l}\text { Potongan } \\
\text { Harga } \\
\text { X1 }\end{array}$} & $\begin{array}{l}\text { Correla } \\
\text { tion } \\
\text { Coeffic } \\
\text { ient }\end{array}$ & 1.000 & .058 & -.029 \\
\hline & & $\begin{array}{l}\text { Sig. (2- } \\
\text { tailed) }\end{array}$ & . & .567 & .775 \\
\hline & & $\mathrm{N}$ & 100 & 100 & 100 \\
\hline & \multirow[t]{3}{*}{$\begin{array}{l}\text { Penataan } \\
\text { Produk } \\
\text { X2 }\end{array}$} & $\begin{array}{l}\text { Correla } \\
\text { tion } \\
\text { Coeffic } \\
\text { ient }\end{array}$ & .058 & 1.000 & -.022 \\
\hline & & $\begin{array}{l}\text { Sig. (2- } \\
\text { tailed) }\end{array}$ & .567 & · & .825 \\
\hline & & $\mathrm{N}$ & 100 & 100 & 100 \\
\hline & \multirow[t]{3}{*}{$\begin{array}{l}\text { Unstandar } \\
\text { dized } \\
\text { Residual }\end{array}$} & $\begin{array}{l}\text { Correla } \\
\text { tion } \\
\text { Coeffic } \\
\text { ient }\end{array}$ & -.029 & -.022 & 1.000 \\
\hline & & $\begin{array}{l}\text { Sig. (2- } \\
\text { tailed) }\end{array}$ & .775 & .825 & \\
\hline & & $\mathrm{N}$ & 100 & 100 & 100 \\
\hline
\end{tabular}

\subsection{Analisis Regresi Liniear Berganda}

Gunanya menggunakan analisis regresi liniear berganda di riset ini yakni untuk mengetahui besarnya pengaruh variabel independent dengan variabel dependent. $\mathrm{Di}$ bawah ini adalah hasil uji analisis liniear berganda:

Tabel 5 Hasil Uji Analisis Liniear Berganda

\begin{tabular}{|l|r|r|}
\hline \multicolumn{1}{c|}{ Coefficients $^{\mathbf{a}}$} \\
\hline \multirow{2}{*}{ Model } & \multicolumn{2}{|c|}{$\begin{array}{c}\text { Collinearity } \\
\text { Statistics }\end{array}$} \\
\cline { 2 - 3 } & Tolerance & \multicolumn{1}{c|}{ VIF } \\
\hline (Constant) & & \\
POTONGAN HARGA X1 & .988 & 1.012 \\
PENATAAN PRODUK X2 & .988 & 1.012 \\
\hline
\end{tabular}

a. Dependent Variable: KEPUTUSAN PEMBELIAN Y Sumber : Data diolah SPSS, 2020

Dari sumber tabel 5 yakni hasil uji analisis liniear berganda menunjukan bahwa nilai regresinya sebagai berikut:

1) Pengujian Hipotesis 1

$\mathrm{H}_{1}=$ potongan harga berpengaruh signifikan terhadap keputusan pembelian.

Dari hasil perhitungan SPSS for Windows versi 22 dalam tabel 5 diperoleh nilai signifikan variabel potongan harga adalah 0,000 . Hal ini menunjukkan bahwa nilai signifikan uji t variabel potongan harga <
0,05 yang berarti $\mathrm{H}_{1}$ diterima. Potongan harga berpengaruh signifikan terhadap keputusan pembelian.

2) Pengujian Hipotesis 2

$\mathrm{H}_{2}=$ Penataan produk berpengaruh signifikan terhadap keputusan pembelian.

Dari hasil perhitungan SPSS for Windows versi 22 dalam tabel 5 diperoleh nilai signifikan variabel potongan harga adalah 0,013 . Hal ini menunjukkan bahwa nilai signifikan uji t variabel penataan produk < 0,05 yang berarti variabel penataan produk berpengaruh signifikan terhadap keputusan pembelian.

\subsection{Hasil Uji Koefisian Determinasi (R2)}

Analisis koefisien determinasi diperoleh nilai Adjusted $R$ sebesar 0,455. Dengan demikian menunjukkan bahwa potongan harga dan penataan produk dapat menjelaskan keputusan pembelian sebesar $45,5 \%$ dan sisanya 54,5\% dijelaskan oleh variabel lain yang tidak dikaji adalah penelitian ini diantaranya lokasi toko, pemberian hadiah, promosi penjualan.

Tabel 6 Uji Koefisien Determinasi

\begin{tabular}{|c|c|c|c|c|}
\hline $\mathrm{M}$ & $\mathrm{R}$ & $\begin{array}{c}\mathrm{R} \\
\text { Square }\end{array}$ & $\begin{array}{c}\text { Adjusted } \\
\text { R } \\
\text { Square }\end{array}$ & $\begin{array}{l}\text { Std. Error of } \\
\text { the Estimate }\end{array}$ \\
\hline & .683 & .466 & .455 & 1.52 \\
\hline
\end{tabular}

a. Predictors: (Constant), PENATAAN BARANG

(X2), POTONGAN HARGA (X1)

\section{SIMPULAN DAN SARAN}

\subsection{Simpulan}

a) Potongan harga secara parsial mempengaruhi signifikan terhadap keputusan pembelian, maksudnya pemberian potongan harga yang ditawarkan membuat konsumen yang terdapat di Matahari Departement Store Pekalongan hendak melaksanakan keputusan pembelian.

b) Penyusunan produk secara parsial mempengaruhi signifikan terhadap keputusan pembelian, maksudnya dengan penyusunan produk yang apik serta menarik membuat konsumen yang terdapat di Matahari Departement Store Pekalongan hendak melaksanakan keputusan pembelian. 
c) Potongan harga serta penyusunan produk secara simultan mempengaruhi terhadap keputusan pembelian pada konsumen Cardinal Shoes Ladies Matahari Departement Store Pekalongan, perihal ini menampilkan kalau potongan harga serta penyusunan produk mempunyai peranan dalam melaksanakan keputusan pembelian.

\subsection{Saran}

Dari hasil riset yang dilakukan oleh peneliti terdapat beberapa saran di antaranya adalah:

a) Dalam pemberian potongan harga yang dilakukan Cardinal Shoes Ladies Matahari Departement Store Pekalongan disarankan untuk terus dilanjutkan karena kebutuhan konsumen dapat terpenuhi.

b) Adanya program potongan harga yang dilakukan oleh Cardinal Shoes Ladies Matahari Departement Store Pekalongan akan menaikkan hasil penjualan dari produk yang dijual dan memicu stimulus atau motivasi membeli dari pembeli apabila mendapatkan potongan harga dari produk yang dibeli.

c) Mengingat variabel potongan harga dan penataan produk dalam riset ini tergolong vital dalam mempengaruhi keputusan pembelian, serta diharapkan riset ini menjadi landasan untuk penelitian selanjutnya guna pengembangan dari riset ini dan meninjau kembali variabel-varibel lainnya seperti lokasi, promosi, pemberi hadiah dan lainnya.

\section{REFERENSI}

Adyarinanda, W. H., \& Yuliati, A. L. (2017). Pengaruh Store Atmosphere terhadap keputusan pembelian (Studi pada konsumen Roemah kopi Bandung ). ISSN : 2355-9357 e-Proceeding of Management : Vol.4, No.2 Agustus 2017| Page 1847.

Asterrina, Hapy; Mashariono. 2013. Pengaruh Discount Terhadap Perilaku Impulse Buying(Studi Pada : Konsumen Centro Departement Store di Margo City) Fakultas Ilmu Sosial dan Politik. Universitas Indonesia.
Dewangga, Aurellius. 2010, Pengaruh Display, Promosi, dan Pelayanan Terhadap Keputusan Pembelian Konsumen. Skripsi, Jurusan Manajemen, Fakultas Ekonomi, Universitas Sanata Dharma Yogyakarta.

Dewi, Indri Kartika. 2018, Pengaruh Diskon Terhadap Keputusan Pembelian Dan Kepuasan Pelanggan Bisnis Online, Journal Administrasi Bisnis, Vol 56 (1), p 2

Didar Adinda, 2013. Pengaruh Promosi dan Potongan Harga Terhadap Keputusan Pembelian Konsumen Pada Butik Fourgirls Medan, Universitas Sumatera Utara. Skripsi.

Dwi, Ary Anjarini, 2017. Analisis Pengaruh Emotional Quotient, Intelligence Quotient dan Spiritual Quotient Terhadap Kepuasan Kerja dan Kinerja Guru di Sekolah Luar Biasa Negeri Batang, Buletin Bisnis \& Manajemen, Vol 3(1), p 28-40.

Prabarini, Anggun, 2018. Pengaruh Promosi Penjualan dan potongan harga terhadap Keputusan pembelian Konsumen Produk Kecantikan Wardah di Toserba Borobudur Kediri , JIMEK Vol 1 No 2

Julastio, Agus. 2017. Pengaruh Discount Price dan Bonus Pack terhadap Impulse Buying melalui Hedonic shopping. Skripsi, Jurusan Manajemen, Fakultas Ekonomi, Universitas Negri Malang.

Kasimin; Dhiana, Patricia; Warso, Muh Mukery. 2014. Effect of Discounts, Sales Promotion and Merchandising on Impulse Buying at Toko IntanPurwokerto, Fakultas Ekonomi: Universitas Pandanaran Semarang.

Kartika, D. M., \& Syahputra. (2017). Pengaruh Store Atmosphere Terhadap Keputusan Pembelian Pada Coffee Shop Di Bandung. Jurnal Ecodemia.

Kotler, P. dan Keller, K.L. 2009. Manajemen Pemasaran. Edisi 12 Jilid 1. Jakarta: Indeks. 
Kotler, Philip and Gary Armstrong. 2012. Principle of Marketing,Edisi Keempat Belas, Pearson Education, New Jersey.

Keller. 2009.Manajemen Pemasaran. Edisi Ketigabelas Jilid 2. Erlangga. Jakarta.

Lipursari, A. (2013). Peran Sistem Informasi Manajemen Dalam Pengambilan Keputusan. Peran Sistem Informasi Manajemen (Sim).

Mamang Sangadji, Etta dan Sopiah, 2010. Metodologi Penelitian, Penerbit Andi, Yogyakarta.

Meidasari M, E., \& Khoirina, S. (2021). Pengaruh Pembelian Price Discount, Bonus Pack dan In-Store Display Terhadap Keputusan Impluse Buying Produk Susu Di HYPERMART Bandar Lampung. JASIORA Jurnal Administrasi Sosial Dan Humaniora, 4(2), 63-70. https://doi.org/10.5281/zenodo.5235020

Moeheriono. 2012, Pengukuran Kinerja Berbasis Kompetensi, Jakarta; Penerbit PT. RajaGrafindo Persada.

Moejikat. 2010. Manajemen Sumber Daya Manusia, Bandung: Penerbit CV. Mandar Maju.

Mulyapradana, A., Hakim, M., Anjarini, A. D., Elshifa, A., \& Huda, S. T. (2021). Implementation of The Academic Information System (SIAKAD) and The Quality of Acamedic Services On User Satisfaction Mediated Decision Making (Case Study On 3 PTS In Pekalongan Residency Area). The 2nd International Conference on Innovation in Social Sciences Education and Engineering. http://conference.loupiasconference.org/in dex.php/ICoISSEE/article/view/23

Mulyapradana, Aria dan Anjarini, Ary Dwi. 2020. The Influence of Entrepreneurship Subjects, Entrepreneurial Motivation, Family Support for Entrepreneurial Decision Making in Pusmanu Polytechnic Office Administration Students. Proceedings of the 2nd International Conference on Strategic Mental
Revolution (ICoSMR), Vol 1 (1), p 162 182.

Mulyapradana, A., Hakim, M., Jamaludin Kharis, A., Muafiq, F., Elshifa, A., Anjarini, A. D., \& Huda, S. T. (2021). The Impact of Office Layout, Work Stress and Management Information Systems on Decision Making is Mediated by Work Productivity for Millennial Generation Employees. The First International Conference on Government Education Management and Tourism (ICoGEMT), 512-520.

http://conference.loupiasconference.org/in dex.php/ICoGEMT/article/view/144/194

Nugroho Sugeng setyo. (2017). PENGARUH DISCOUNT, DISPLAY PRODUK, DAN LOKASI TOKO TERHADAP KEPUTUSAN PEMBELIAN DI TOKO D'SPORT KEDIRI. Simki-Economic Vol 1 No 1 , Kediri

Rohmat, Saepul. 2010, Pengaruh Produktivitas Tenaga Kerja Terhadap kinerja perusahaan, Jurnal Unsil, Vol 387, p 10

Putri, Yessica Tri Amanda ; Muhammad Edwar. 2014.Pengaruh Bonus Pack Dan Price Discount Terhadap Impulse Buying Pada Konsumen Giant Hypermarket Diponegoro Surabaya, Fakultas Ekonomi : Universitas Negeri Surabaya.

Prihastama, Brian Vicky. 2016. Pengaruh Price Discount Dan Bonus Pack Terhadap Impulse Buying Pada Pelanggan Minimarket (Studi pada Pelanggan Minimarket Indomaret Jl. Demangan Baru, Depok, Sleman, Yogyakarta). Fakultas Ekonomi: Universitas Negeri Yogyakarta.

Sekaran, Uma. 2007.Metodologi Penelitian Untuk Bisnis,Edisi Keempat.Salemba Empat: Jakarta.

Sugiyono, 1999.Metode Penelitian Bisnis. Alfabeta: Bandung.

2013. Metode Penelitian Pendidikan. Alfabeta: Bandung. 2014.Metode Penelitian Pendidikan 
Pendekatan Kuantitatif, Kualitatif, dan

R\&D. Alfabeta: Bandung.

Tukino. (2014). Pengaruh Kualitas Sistem Informasi Manajemen dan Struktur Organisasi terhadap Efektivitas Pengambilan Keputusan pada PT UT Quality Indonesia. Computer Based Information System Journal.

Widodo, S. S. (2017). Pengaruh Discount, Display Produk dan Lokasi Terhadap Keputusan Pembelian Di Toko D'Spot Kediri. Simki-Economic, 1(1), 2-8. http://simki.unpkediri.ac.id/mahasiswa/file _artikel/2017/07dd43ab928882eb1eecf51f ba983218.pdf 